\title{
Incident atrial fibrillation in the emergency department in Ontario: a population-based retrospective cohort study of follow-up care
}

\author{
Clare L. Atzema MD MSc, Bing Yu PhD, Noah Ivers MD PhD, Paula Rochon MD MPH, \\ Douglas S. Lee MD PhD, Michael J. Schull MD MSc, Peter C. Austin PhD
}

\section{Abstract}

Background: Continuity of care has been shown to be poor following in-hospital discharge, and there are substantially fewer resources to facilitate follow-up care arrangements after discharge from an emergency department. Our objective was to assess the frequency, timeliness and predictors for obtaining follow-up care following discharge from an emergency department in Ontario with a new diagnosis of atrial fibrillation.

Methods: We conducted a retrospective cohort study involving all patients discharged from the 157 nonpediatric emergency departments in Ontario, who received a new diagnosis of atrial fibrillation between 2007 and 2012 . We determined the frequency of follow-up care with a family physician, cardiologist or internist within 7 (timely) and 30 days of the emergency department visit, and assessed the association of emergency and family physician characteristics, including primary care model type, with obtaining timely follow-up care.

Results: Among 14907 patients discharged from Ontario emergency departments with a new, primary diagnosis of atrial fibrillation, half $(n=7473)$ had timely follow-up care. At 30 days, 2678 patients $(18.0 \%)$ still had not obtained follow-up care. Among emergency and family physician factors, lack of a family physician had the largest independent association with acquiring timely follow-up care (odds ratio [OR] $0.58,95 \%$ confidence interval [Cl] 0.50-0.69). Using patients with a family physician belonging to a primarily fee-for-service remuneration model as the comparison group, patients with a family physician belonging to a capitation-based Family Health Network, as part of a Family Health Team, were less likely to receive timely follow-up care (OR $0.73,95 \% \mathrm{Cl} 0.62-0.86$ ), as were those whose family physician belonged to the same model type that was not part of a Family Health Team (OR 0.77, 95\% Cl 0.60-0.97).

Interpretation: Only half of the patients who were discharged from an emergency department in Ontario with a new diagnosis of atrial fibrillation were seen within 7 days of discharge. The most influential factor was having a family physician; patients with a family physician being remunerated via primarily fee-for-service methods were more likely to be seen within 7 days than those who were reimbursed through a primarily capitation model. Systems-wide solutions are needed to ensure timely follow-up care is available for all patients with chronic diseases.

trial fibrillation is a common cardiovascular disease, and its prevalence is projected to increase by $250 \%$ by the year $2050 .^{1,2}$ It is estimated that more than $15 \%$ of strokes are due to atrial fibrillation, ${ }^{3,4}$ and these strokes have a 1 -year mortality rate of $50 \% .{ }^{5}$ The prognosis of some diseases worsens in the setting of atrial fibrillation, ${ }^{6,7}$ and atrial fibrillation itself is associated with an independent increase in mortality among both sexes. ${ }^{8}$

Atrial fibrillation is seen frequently in the emergency department. ${ }^{9}$ Guidelines recommend that most of these patients need not be admitted to hospital but should be discharged from the emergency department with follow-up care arranged. ${ }^{10}$ Timely follow-up care is required to either initiate or continue (if the emergency department physician offered a prescription) an oral anticoagulant medication, such as warfarin, to prevent strokes, ${ }^{10-12}$ and rate-control medication to prevent tachycardiomyopathy, ${ }^{10-12}$ as well as to improve patient quality of life. ${ }^{13}$
Therefore, timely follow-up care is important. In the setting of a new diagnosis, it includes evaluation by a cardiologist. ${ }^{10,14}$

Beginning in the early 2000s, several primary care models were introduced in Ontario; before the introduction of these

Competing interests: Clare Atzema has received a grant in the form of a New Investigator Award from the Heart and Stroke Foundation of Ontario (HSFO). Peter Austin has received a grant in the form of a Career Investigator Award from the HSFO. Michael Schull has received a grant from the Applied Chair in Health Services and Policy Research of the Canadian Institutes of Health Research (CIHR). Noah Ivers received a grant in the form of a New Investigator Award and Douglas Lee received a grant in the form of a Clinician Scientist Award from CIHR. No competing interests were declared by the other authors.

This article has been peer reviewed.

Correspondence to: Clare Atzema, clare.atzema@ices.on.ca.

CMAJ Open 2015. DOI:10.9778/cmajo.20140099 
models, most family physicians were reimbursed for their services via fee-for-service billing claims. The new models ranged from mostly capitation-based reimbursement (Family Health Network or Organization, the latter offering a larger number of services to patients than the former) to mostly fee-for-service (Family Health Group if 3 or more physicians, or Comprehensive Care Model if fewer than 3 physicians). All of the new models required physicians to formally enrol patients and to provide after-hours care (Table 1). The Family Health Team is not a reimbursement model, but it is a model that is meant to facilitate the development of a patient-centred medical home, with funding for an interdisciplinary team, an executive director and electronic medical records. It is only available to physicians in the capitation-based reimbursement models (Appendix 1, available at www.cmajopen.ca/content/3/2/E182/ suppl/DC1). ${ }^{16}$ Although these models were introduced to improve access to care, among other reasons, few studies have evaluated outcomes, such as access to care for specific patient groups. ${ }^{15,17}$ In this study, we examined whether follow-up care after an emergency department visit for a new diagnosis of atrial fibrillation was associated with emergency department physician or family physician characteristics, including the type of primary care model used by the family physician.

\section{Methods}

\section{Study design and data sources}

Data sources included multiple administrative databases that contain information on all medically necessary (under universal health care coverage) visits and billings in Ontario. Ontario is Canada's most populous province, with an ethnically diverse population of 13 million. ${ }^{18}$

The study cohort was identified using the National Ambulatory Care Reporting System of the Canadian Institute for Health Information, which contains anonymized, abstracted data for all emergency department visits in Ontario. Up to 10 diagnoses are collected using the International Statistical Classification of Diseases and Related Health Problems, 10th revision codes. We previously validated the code for atrial fibrillation (1480) in this dataset. ${ }^{9}$ Emergency visit data were linked via the encoded Ontario health card number to the Discharge Abstract Database of the Canadian Institute for Health Information, which contains all hospitalizations; the Registered Persons Database of the Ontario Ministry of Health and Long-term Care, which contains validated mortality data (including out-of-hospital deaths); ${ }^{19}$ and the Ontario Health Insurance Plan, which contains all billings in Ontario paid for by universal health care (by all physician types, in any setting). Physician specialty was determined using a derived physician database, which is comprised of information from the Ontario Health Insurance Plan and their Corporate Provider Database, and the Ontario Physician Human Resources Data Centre database. ${ }^{20}$ The latter, whose mandate is to monitor physician supply in Ontario, receives specialty information from the College of Physicians and Surgeons of Ontario and the Corporate Provider Database; it also conducts an annual telephone survey of one-third of all physicians to determine which specialty best describes their current practice. Thus, the specialty information for each physician is validated about once every 3 years. Where emergency department visits could not be linked to an emergency physician billing code, missing data on managing physician characteristics were imputed using multiple imputation.

We determined the name of the patient's family physician using the Client Agency Program Enrolment (Ontario Ministry of Health and Long-term Care) tables, and the physician's primary care model type was determined using the Corporate Provider Database. If the patient was not enrolled with a family physician during the year of the emergency department visit (a small number of patients), we used a virtual rostering method to assign these remaining patients to a family physician, whereby the patient was assigned to the family physician with whom they had most of their primary care services in the 2 years before the emergency visit. If the patient was not enrolled with a family physician and could not be assigned using virtual rostering (i.e., no primary care visits), the patient was assigned to the no family physician group. In a sensitivity analysis, we examined the results if all patients were assigned to a family physician using the virtual rostering method. ${ }^{21}$ This method tends to assign healthy patients to the no family physician group because they have not seen a family physician in several years, when in fact they may have a family physician.

This retrospective cohort study received ethics approval from the Sunnybrook Health Sciences Centre Research Ethics Board.

\section{Study population}

We included patients aged 18 years and older with a primary emergency department diagnosis of atrial fibrillation, a valid Ontario health card number and who were seen in an Ontario emergency department between Apr. 1, 2007, and Mar. 31, 2012. The primary diagnosis is the first diagnosis written on the emergency department chart (by the emergency department physician). Only the first, or index, visit during the study period was retained. Patients who died in the emergency department were excluded. Patients who were admitted to hospital were excluded because the goal of the study was to ascertain how quickly patients who were discharged from an emergency department obtained follow-up care (particularly because of the projected increase in chronic disease care in emergency departments ${ }^{22}$ and the anticipated need to decrease costly hospitalizations ${ }^{23}$ ). Excellent studies on transitions of care from the in-hospital setting have been performed, ${ }^{24}$ but discharge from an emergency department represents a very different scenario: these patients do not receive daily assessment by a physician, such as vital sign checks and diagnostic testing, when sent back to their homes.

Specialty emergency departments (i.e., solely pediatric or mental health) and those that were not open 24 hours a day were excluded. We excluded patients who were given a low acuity triage score (Canadian Triage and Acuity Scale score of 4 or 5$)^{25}$ and patients with a history of atrial fibrillation or flutter, defined as an emergency department visit, hospitalization or outpatient visit for atrial fibrillation or flutter in the 5 years before the index date. 
Patients were followed for up to 30 days after discharge from the emergency department for a billing from a family physician, a cardiologist or an internist. Patient comorbidities were determined using validated algorithms, where available, ${ }^{26-30}$ or using either 1 hospitalization code or 2 outpatient visit codes in the 5 years before the emergency department visit. Patients were divided into income categories based on the median household income in their neighbourhood using Statistics Canada Census data for 2006; postal codes were used to form quintiles based on average income in the dissemination area. ${ }^{31}$ A rural residence was defined using the Statistics Canada definition of an area of less than 10000 residents, and immigration status was determined using Citizenship and Immigration Canada data.

\section{Outcome measures}

The primary outcome measure was the proportion of patients who received outpatient follow-up care with a family physician, a cardiologist or an internist within 7 days of being discharged from the emergency department. Because atrial fibrillation guidelines do not specifically define a time period within which a patient with incident atrial fibrillation should receive care, ${ }^{10-12}$ we chose 7 days based on other cardiovascular diseases. ${ }^{32,33}$ Our 7 -site survey of emergency department physi- cians found that most chose 7 days for follow-up after emergency department discharge with a diagnosis of severe hypertension $;{ }^{32}$ survey work on the discharge from emergency departments of patients with atrial fibrillation had similar findings (unpublished data, 2009). Outcomes for heart failure are better if follow-up occurs within 7 days of discharge from hospital. ${ }^{33}$ Therefore, the available sources suggested that 7 days is a consistent, recommended time frame for follow-up care after discharge from the emergency department for a chronic cardiovascular disease. To address variation in what might be considered optimal time to follow-up care, secondary outcome measures included the proportion of patients with rapid (within $3 \mathrm{~d}$ ) and delayed (within $30 \mathrm{~d}$ ) follow-up care, as well as the adjusted association of emergency and family physician characteristics with obtaining follow-up care.

\section{Primary data analyses}

Descriptive statistics were used for the proportion of patients who accessed follow-up care. Because deaths were infrequent in this cohort, we used logistic regression modelling to regress patient- and provider-level factors on receipt of timely followup care, creating separate models for rapid and delayed care. Robust variance estimates were used to account for the clustering of patients within emergency departments. In a sensi-

Table 1: Characteristics of Ontario primary care models ${ }^{15}$

\begin{tabular}{|c|c|c|}
\hline Characteristic & Enhanced fee-for-service model & Capitation model \\
\hline Patient enrolment & Optional & Required \\
\hline After-hours call & Required & Required \\
\hline Fee-for-service payment & $\begin{array}{l}\text { Full payment plus } 10 \% \text { premium for } 21 \\
\text { comprehensive care services }\end{array}$ & $\begin{array}{l}\text { Payment at } 10 \% \text { of full rate for } 56 \text { services } \\
\text { for enrolled patients; established maximum } \\
\text { fee-for-service payments annually }\end{array}$ \\
\hline Extended hours & $\begin{array}{l}\text { One 3-hr evening or weekend session per physician } \\
\text { per wk, to a maximum of } 5 \text { sessions; exempted if } \\
>50 \% \text { of physicians provide emergency, anesthesia } \\
\text { or obstetrics coverage }\end{array}$ & Same as enhanced fee-for-service model \\
\hline After-hours care & $\begin{array}{l}\text { Additional } 20 \% \text { of fee-for-service payment for } \\
\text { enrolled and virtually enrolled patients for } 9 \text { basic } \\
\text { office services }\end{array}$ & Same as enhanced fee-for-service model \\
\hline Access bonus & NA & $\begin{array}{l}\text { Additional payment, reduced if enrolled patient sees } \\
\text { an nonspecialist physician outside of group }\end{array}$ \\
\hline $\begin{array}{l}\text { Group management and } \\
\text { leadership }\end{array}$ & NA & Annual fee per enrolled patient \\
\hline $\begin{array}{l}\text { Management of care for } \\
\text { heart failure }\end{array}$ & $\begin{array}{l}\text { Annual fee per enrolled patient for coordinating, } \\
\text { providing and documenting required elements of } \\
\text { care for heart failure }\end{array}$ & Same as enhanced fee-for-service model \\
\hline Unattached patient fee & $\begin{array}{l}\text { A one-time fee for enrolling an acute care patient } \\
\text { without a family physician following discharge from } \\
\text { an inpatient hospital stay }\end{array}$ & Same as enhanced fee-for-service model \\
\hline New patient premium & $\begin{array}{l}\text { A one-time fee for up to } 60 \text { enrolled new patients } \\
\text { without a family physician; increase in fee for } \\
\text { patients aged } 65-74 \mathrm{yr} \text {, and a further increase in } \\
\text { fee for patients aged } 75 \mathrm{yr} \text { and over }\end{array}$ & Same as enhanced fee-for-service model \\
\hline
\end{tabular}


tivity analysis, we performed the timely analysis using the Cox proportional hazards model, with patient death and hospitalization treated as censoring events.

To evaluate whether an association between primary care model type and receipt of follow-up care might change over time, a Cox proportional hazards model with the same variables was regressed on follow-up care within 30 days, and an interaction term was introduced. A significant interaction between primary care model type and time (in days) in the model indicates that the hazard of receiving follow-up care, for patients with a family physician in that primary care model type, changed over the 30 day period. From the interaction variable we calculated the hazard of obtaining follow-up care on days 14 and 30 by primary care model type, in patients who had not yet obtained follow-up care (e.g., they had not yet had an event), using the following equation: $\mathrm{e}^{[\mathrm{HR}}{ }_{1}+[\mathrm{no}$ of days( $\left.\left.\mathrm{HR})\right]\right\}$, where $\mathrm{HR}_{1}$ is the hazard ratio associated with that primary care model type, and $\mathrm{HR}_{2}$ is the hazard ratio associated with the interaction term for that primary care model type.

In a second sensitivity analysis, we repeated the model of obtaining timely care with assignment of patients solely by the virtual rostering method. All analyses were performed with SAS software (Version 9.2; SAS Institute Inc., Cary, North Carolina).

\section{Results}

There were 14907 qualifying patient visits to an emergency department made at 157 emergency departments between Apr. 1, 2007, and Mar. 31, 2012 (Table 2). Of these patients, $14146(94.9 \%)$ had a family physician; $7473(50.1 \%)$ had follow-up care with a family physician, a cardiologist or an internist within 7 days after discharge (Table 3); 4085 (27.4\%) acquired follow-up care within 3 days and $12229(82.0 \%)$ within 30 days. Most of the care was provided by the family physician. One hundred and twenty patients $(<1.0 \%)$ died within 30 days after discharge.

In the logistic regression model involving all 14907 study participants, the factor with the strongest association with achieving timely follow-up care was not having a family physician (odds ratio [OR] $0.58,95 \%$ confidence interval [CI] 0.50 0.69). In the model involving the 14146 participants who had a family physician, those with a family physician in capitationbased models (Family Health Network or Organization) had a decreased odds of obtaining timely follow-up care, regardless of whether the physician functioned as part of a Family Health Team (OR 0.73 and 0.77 when part of a Family Health Team; OR 0.84 and 0.86 when not part of a Family Health Team), compared with patients with a family physician in a primarily fee-for-service model (Table 4 and Appendix 1). Compared with the latter patients, there was no difference for patients whose family physician was remunerated via traditional fee-forservice billings (OR 0.94, 95\% CI 0.82-1.07). No emergency department physician characteristics were independently associated with obtaining timely follow-up care.

Results were similar in the 3- and 30-day (Appendix 1) models, with the exception of the traditional fee-for-service variable, which was associated with lower odds of obtaining follow-up care in the 30-day model than primarily fee-for-service model patients. In the sensitivity analyses, results were similar using a Cox proportional hazards model, and where patients were assigned to the family physician using a virtual rostering method.

The interaction between time and primary care model type was significant for all model types except for traditional feefor-service and the capitation-based Family Health Organization (with a Family Health Team). We calculated that at 14 days (among patients who were still not seen by 14 days after the emergency department visit), the differences between the capitation-based groups and the primarily fee-for-service models were attenuated: the hazard of being seen on day 14 was $0.91,0.85$, and 0.91 for the capitation-based models Family Health Network with a Family Health Team, without a Family Health Team, and Family Health Organization without a Family Health Team, respectively, compared with patients whose family physician was reimbursed via the primarily fee-for-service models. At 30 days postdischarge (only among patients who had not obtained follow-up care), the hazard of being seen on day 30 was higher in most of the capitation-based model groups, compared with primarily fee-forservice model patients: 1.20, 1.11 and 1.02 for Family Health Network with a Family Health Team, without a Family Health Team and Family Health Organization without a Family Health Team, respectively.

\section{Interpretation}

\section{Main findings}

In this population-based study, we found that only half of the patients with a new diagnosis of atrial fibrillation obtained follow-up care within a week of an emergency department visit. The proportion increased to $82 \%$ at 30 days, leaving $18 \%$ of patients without ongoing care for their disease. Not surprisingly, after adjustment for many patient- and providerlevel characteristics, the most important factor in obtaining follow-up care was if the patient had a family physician. Fortunately, only $5 \%$ of the patients did not have a family physician. This suggests that policy-makers in Ontario should shift their emphasis from matching patients with a family physician to improving timely access to them. Interestingly, emergency department physician characteristics, including physician age, sex and years of practice, were not associated with receipt of timely follow-up care for these patients.

We found that patients with a family physician belonging to a capitation-based primary care model were $14 \%-28 \%$ less likely to be seen by a family physician or specialist within a week of emergency department discharge, compared with patients with a family physician who was reimbursed via primarily fee-for-service models. Patients with a family physician who was reimbursed through traditional fee-for-service billings had similar access as the primarily fee-for-service model patients. It may be that the patient-bypatient billing in the fee-for-service models provides more incentive to fit the emergency department patient into a tight schedule; or it may be that capitation-based groups have such a high number of rostered patients that they can- 
not see unplanned patients within a week. Future studies are needed to examine the reasons behind the difference, including scheduling practices. ${ }^{34}$

\section{Comparison with other studies}

It is not known if this difference in access to follow-up care impacts patient outcomes. Low rates of follow-up care have

\section{Table 2 (part 1): Characteristics of the study population}

Variable

\section{Patient characteristics}

Age, yr; mean \pm SD

Male

Income quintile

$$
\begin{aligned}
& 1 \\
& 2 \\
& 3 \\
& 4 \\
& 5
\end{aligned}
$$

Rural residence

Long-term care or nursing home residence

Immigrant

Past medical history

Hypertension, recent diagnosis (in the last yr)

Hypertension, diagnosis made before the last $1 \mathrm{yr}$

Heart failure, recent diagnosis (in the last yr)

Heart failure, diagnosis made before the last $1 \mathrm{yr}$

Acute myocardial infarction

Coronary artery disease

Coronary artery bypass graft

Stroke

Diabetes mellitus

Dementia

Chronic obstructive pulmonary disease

Asthma

Renal failure

Nonmetastatic cancer

Metastatic cancer

$\mathrm{CHADS}_{2}$ score $\geq 2$

ADG score, mean \pm SD

Emergency department visit characteristics

Emergency department triage score ( 1 = highest acuity)

1 or 2

3

No. of patients who arrived by ambulance

Time of day patient presented to emergency department

00:00-07:59

$08: 00-15: 59$

16:00-23:59

Day of week patient presented to emergency department

Weekday

Emergency department physician, sex

\begin{tabular}{lr} 
Unknown & $1895(12.7)$ \\
\hline Female & $2581(17.3)$ \\
\hline Male & $10431(70.0)$ \\
\hline Emergency department physician, specialty & $5875(39.4)$ \\
\hline Emergency medicine (3-yr program) & $1962(13.2)$ \\
Emergency medicine (5-yr program) & $3832(25.7)$ \\
Family medicine & $1345(9.0)$ \\
Other & $1893(12.7)$ \\
Unknown &
\end{tabular}

No. of patients (\%)

$$
n=14907
$$

$65.2 \pm 15.9$

$7942(53.3)$

$2491(16.7)$

$2893(19.4)$

$2913(19.5)$

$3198(21.5)$

$3412(22.9)$

$2088(14.0)$

$248 \quad(1.7)$

$1195(8.0)$

$419(2.8)$

$8699(58.4)$

225 (1.5)

$787 \quad(5.3)$

$2156(14.5)$

1726 (11.6)

361 (2.4)

541 (3.6)

$2896(19.4)$

550 (3.7)

2426 (16.3)

2014 (13.5)

$527 \quad(3.5)$

1895 (12.7)

$252(1.7)$

$5830(39.1)$

$9.9 \pm 4.2$

$9916(66.5)$

4991 (33.5)

4074 (27.3)

$2872(19.3)$

7640 (51.3)

4395 (29.5)

11492 (77.1)

3415 (22.9)

$1895(12.7)$

2581 (17.3)

$5875(39.4)$

1962 (13.2)

$1345 \quad(9.0)$

$893(12.7)$ 
Table 2 (part 2): Characteristics of the study population

\begin{tabular}{|c|c|}
\hline Variable & $\begin{array}{c}\text { No. of patients (\%)* } \\
\quad n=14907\end{array}$ \\
\hline \multicolumn{2}{|c|}{ Emergency department physician, no. of years of practice; $y r$} \\
\hline $0-3$ & $1900(12.7)$ \\
\hline $4-10$ & $3686(24.7)$ \\
\hline $11-20$ & $4219(28.3)$ \\
\hline$>20$ & $3159(21.2)$ \\
\hline Unknown & $1943(13.0)$ \\
\hline \multicolumn{2}{|l|}{ Hospital type } \\
\hline Community & $11285(75.7)$ \\
\hline Small & $836(5.6)$ \\
\hline Teaching & $2786(18.7)$ \\
\hline \multicolumn{2}{|l|}{ Family physician characteristics } \\
\hline \multicolumn{2}{|l|}{ Family physician, sex } \\
\hline Female & $3804(25.5)$ \\
\hline Male & $10333(69.3)$ \\
\hline Unknown & $770(5.2)$ \\
\hline \multicolumn{2}{|l|}{ Family physician, main specialty } \\
\hline Family medicine & $13981(93.8)$ \\
\hline Emergency medicine & $146 \quad(1.0)$ \\
\hline Unknown & $780 \quad(5.2)$ \\
\hline \multicolumn{2}{|c|}{ Family physician, no. of years of practice; $y r$} \\
\hline $0-5$ & $542(3.6)$ \\
\hline $6-10$ & $901 \quad(6.0)$ \\
\hline $11-15$ & $1353(9.1)$ \\
\hline$>15$ & $11329(76.0)$ \\
\hline Unknown & $782(5.2)$ \\
\hline No. of patients with a family physician & $14146(94.9)$ \\
\hline \multicolumn{2}{|l|}{ Family physician's model type } \\
\hline $\mathrm{CCM} \dagger$ or FHG $\ddagger$ & $6613(44.4)$ \\
\hline FHN§ with FHT & $692(4.6)$ \\
\hline FHN§ without FHT & $315(2.1)$ \\
\hline FHO川 with FHT & $2271(15.2)$ \\
\hline FHOף without FHT & $3189(21.4)$ \\
\hline $\mathrm{FFS}^{* *}$ & $1066 \quad(7.2)$ \\
\hline Family physician belongs to an FHT & $2963(19.9)$ \\
\hline \multicolumn{2}{|l|}{$\begin{array}{l}\text { Note: } A D G=\text { aggregated diagnosis group, } C C M \\
\text { FHG = family health group, } F H N=\text { family health } \\
\text { *Unless otherwise specified. } \\
\text { †Primarily fee for service, }<3 \text { physicians. } \\
\text { †Primarily fee for service, } \geq 3 \text { physicians. } \\
\text { §Primarily capitation, small basket of services. } \\
\text { १Primarily capitation, large basket of services. } \\
\text { **Traditional fee for service. }\end{array}$} \\
\hline
\end{tabular}

Table 3: Follow-up care among patients $(n=14$ 907) discharged from an emergency department in Ontario with a new diagnosis of atrial fibrillation

\begin{tabular}{|c|c|c|c|c|c|c|c|c|c|}
\hline \multirow{2}{*}{$\begin{array}{l}\text { Time to } \\
\text { follow- } \\
\text { up } \\
\text { care, d }\end{array}$} & \multirow[b]{2}{*}{$\begin{array}{c}\text { Total no. of } \\
\text { patients seen (\%) }\end{array}$} & \multirow{2}{*}{$\begin{array}{l}\text { No. of patients } \\
\text { with follow-up care } \\
\text { from family } \\
\text { physician only (\%) }\end{array}$} & \multirow{2}{*}{$\begin{array}{l}\text { No. of patients } \\
\text { with follow-up care } \\
\text { from cardiologist } \\
\text { or internist only } \\
\text { (\%) }\end{array}$} & \multirow{2}{*}{$\begin{array}{l}\text { No. of patients } \\
\text { with follow-up care } \\
\text { from cardiologist } \\
\text { or internist, with or } \\
\text { without family } \\
\text { physician (\%) }\end{array}$} & \multirow{2}{*}{$\begin{array}{l}\text { No. of patients } \\
\text { with follow-up care } \\
\text { from both family } \\
\text { physician and } \\
\text { cardiologist or } \\
\text { internist (\%) }\end{array}$} & \multirow{2}{*}{$\begin{array}{l}\text { No. of patients with } \\
\text { follow-up care from } \\
\text { any of family } \\
\text { physician, } \\
\text { cardiologist or } \\
\text { internist }(\%)\end{array}$} & \multicolumn{3}{|c|}{$\begin{array}{l}\text { No. of patients who died } \\
\text { after discharge }\end{array}$} \\
\hline & & & & & & & $\begin{array}{l}\text { Within } \\
3 \mathrm{~d}\end{array}$ & $\begin{array}{l}\text { Within } \\
7 \mathrm{~d}\end{array}$ & $\begin{array}{l}\text { Within } \\
30 \mathrm{~d}\end{array}$ \\
\hline $1-3$ & $4085(27.4)$ & 3094 (20.8) & 787 (5.3) & $991 \quad(6.7)$ & $204 \quad(1.4)$ & $4085(27.4)$ & 14 & 21 & 61 \\
\hline $1-7$ & $7473(50.1)$ & 5311 (35.6) & 1414 (9.5) & 2162 (14.5) & $748 \quad(5.0)$ & $7473(50.1)$ & 14 & 34 & 97 \\
\hline $1-30$ & 12229 (82.0) & $6473(43.4)$ & $1765(11.8)$ & 5756 (38.6) & 3991 (26.8) & 12229 (82.0) & 14 & 34 & 120 \\
\hline$>30$ & 2678 (18.0) & - & - & - & - & - & 6 & 14 & 24 \\
\hline
\end{tabular}


been reported for older patients who have visited emergency departments (regardless of need for follow-up), ${ }^{35}$ with better rates $(73 \%)$ among patients with chest pain who were directly referred for a stress test. ${ }^{36}$ The patient with newly diagnosed atrial fibrillation who has not received follow-up care is likely to have gone unprotected from a stroke; however, the risk is

Table 4 (part 1): Adjusted odds of obtaining follow-up care from a family doctor, cardiologist or internist within 7 days of emergency department discharge among patients who had a family physician $(n=14146)$

\begin{tabular}{|c|c|c|}
\hline Variable & OR $(95 \% \mathrm{Cl})$ & $p$ value \\
\hline \multicolumn{3}{|l|}{ Patient characteristics } \\
\hline Age, per decade increase & $1.09(1.06-1.12)$ & $<0.001$ \\
\hline Female & $1.05(0.98-1.13)$ & 0.18 \\
\hline \multicolumn{3}{|l|}{ Income quintile; referent $=1$, lowest } \\
\hline 2 & $1.07(0.96-1.20)$ & 0.22 \\
\hline 3 & $1.04(0.93-1.16)$ & 0.53 \\
\hline 4 & $0.95(0.85-1.06)$ & 0.34 \\
\hline 5 (highest) & $1.05(0.94-1.17)$ & 0.40 \\
\hline Rural residence & $0.95(0.85-1.07)$ & 0.44 \\
\hline Long-term care or nursing home residence & $0.77(0.56-1.05)$ & 0.09 \\
\hline Immigrant & $1.18(1.04-1.34)$ & 0.01 \\
\hline \multicolumn{3}{|l|}{ Past medical history; referent $=0$} \\
\hline Hypertension, recent diagnosis (in the last yr) & $1.14(0.92-1.40)$ & 0.23 \\
\hline Hypertension, diagnosis made before the last $1 \mathrm{yr}$ & $1.15(1.06-1.26)$ & 0.002 \\
\hline Heart failure, recent diagnosis (in the last yr) & $0.87(0.65-1.14)$ & 0.31 \\
\hline Heart failure, diagnosis made before the last $1 \mathrm{yr}$ & $0.75(0.64-0.88)$ & $<0.001$ \\
\hline Acute myocardial infarction & $1.02(0.92-1.14)$ & 0.68 \\
\hline Coronary artery disease & $0.83(0.73-0.94)$ & 0.003 \\
\hline Coronary artery bypass graft & $1.09(0.85-1.40)$ & 0.49 \\
\hline Stroke & $0.78(0.65-0.94)$ & 0.01 \\
\hline Diabetes mellitus & $1.06(0.96-1.17)$ & 0.24 \\
\hline Dementia & $0.84(0.69-1.03)$ & 0.09 \\
\hline Chronic obstructive pulmonary disease & $1.03(0.93-1.13)$ & 0.58 \\
\hline Asthma & $1.04(0.94-1.15)$ & 0.44 \\
\hline Renal failure & $0.69(0.57-0.83)$ & $<0.001$ \\
\hline Nonmetastatic cancer & $0.84(0.76-0.94)$ & 0.002 \\
\hline Metastatic cancer & $0.94(0.72-1.22)$ & 0.62 \\
\hline CHADS2 score $\geq 2$; referent $=0$ or 1 & $0.97(0.87-1.09)$ & 0.65 \\
\hline ADG score per 1 point increase & $1.04(1.03-1.05)$ & $<0.001$ \\
\hline \multicolumn{3}{|l|}{ Emergency department visit characteristics } \\
\hline Emergency department triage score of 1 or 2 (high acuity); referent $=3,4$ or 5 & $1.02(0.94-1.09)$ & 0.69 \\
\hline Patients who arrived by ambulance & $0.99(0.91-1.07)$ & 0.77 \\
\hline \multicolumn{3}{|l|}{ Time of day patient presented to the emergency department } \\
\hline $00: 00-07: 59$ & $0.89(0.81-0.98)$ & 0.01 \\
\hline 16:00-23:59 & $0.93(0.86-1.00)$ & 0.05 \\
\hline Day of week patient presented to the emergency department, weekend & $0.94(0.87-1.03)$ & 0.17 \\
\hline Emergency department physician, age per decade increase & $0.97(0.84-1.12)$ & 0.62 \\
\hline Emergency department physician, female & $1.06(0.93-1.20)$ & 0.34 \\
\hline \multicolumn{3}{|l|}{ Emergency department physician, main specialty; referent = family medicine training } \\
\hline Emergency medicine (3-yr program) & $0.90(0.76-1.05)$ & 0.16 \\
\hline Emergency medicine (5-yr program) & $0.91(0.75-1.10)$ & 0.29 \\
\hline Other & $0.93(0.57-1.53)$ & 0.73 \\
\hline \multicolumn{3}{|l|}{ Emergency department physician, no. of years of practice; yr } \\
\hline $4-10$ & $1.03(0.91-1.16)$ & 0.38 \\
\hline $11-20$ & $0.98(0.83-1.15)$ & 0.85 \\
\hline$>20$ & $0.98(0.73-1.30)$ & 0.86 \\
\hline
\end{tabular}


relatively low within a week after discharge..$^{37,38}$ The risk of tachycardia-induced cardiomyopathy varies depending on the duration and degree of tachycardia and the underlying heart function. The symptoms of atrial fibrillation may result in multiple emergency department visits if they are not managed. If the patient had not been seen by a family physician, cardiologist or an internist at 30 days after discharge, the impact of the family physician's primary care model type on receiving care was removed; however, given that emergency physicians want their patients with hypertension seen within 7 days, ${ }^{32}$ it is unlikely that they would recommend 30 days for follow-up in patients with a new diagnosis of atrial fibrillation. Studies on short- and long-term outcomes related to the timing of follow-up care are needed to validate the optimal time for follow-up.

If emergency department physicians cannot be sure of timely follow-up care, the usual solution is hospital admission. Patients in hospital receive daily evaluations by a physician and frequent assessment of their vital signs, have their anticoagulation treatment managed and receive diagnostic tests; this is in contrast to the patient who is discharged from the emergency department to home, who may have their condition worsen, unchecked, over many days. However, admissions to hospital constitute about $80 \%$ of the cost of managing atrial fibrillation, ${ }^{39}$ and with a predicted $250 \%$ in its prevalence by the year $2050,1,2$ admitting the same proportion of these patients to hospital is not sustainable (38\% in Ontario; 70\% of emergency department visits for atrial fibrillation in the United States result in the patient being admitted to hospital).$^{40}$ Improving follow-up using a systematic process to ensure timely outpatient follow-up care is a cost-effective solution that could diminish the need for immediate admission to hospital. Currently, patients operate as the conduit between the emergency department and follow-up care; although feasible and probably safe for younger patients, contacting the physician's office and relaying the diagnosis may be more challenging for older patients, the very patients who are at the highest risk of a poor outcome without follow-up care.

\section{Limitations}

While the Client Agency Program Enrolment tables are updated annually, their size (13 million Ontarians) results in some delay in capturing patients who change physicians. To assess the impact of this delay, we performed a sensitivity analysis that assigned patients to their most frequently visited physician: the results did not change substantially. Bias is possible because of the potential for underbilling in capitationbased practices. For example, nurses may provide care for practices with Family Health Teams; however, this is unlikely to account for the differences observed because the findings were the same for capitation-based practices that were not part of a Family Health Team. Capitated providers are incentivized to conduct follow-up by phone or email, which would not result in a billing; however, an assessment of a new diag-

Table 4 (part 2): Adjusted odds of obtaining follow-up care from a family doctor, cardiologist or internist within 7 days of emergency department discharge among patients who had a family physician $(n=14146)$

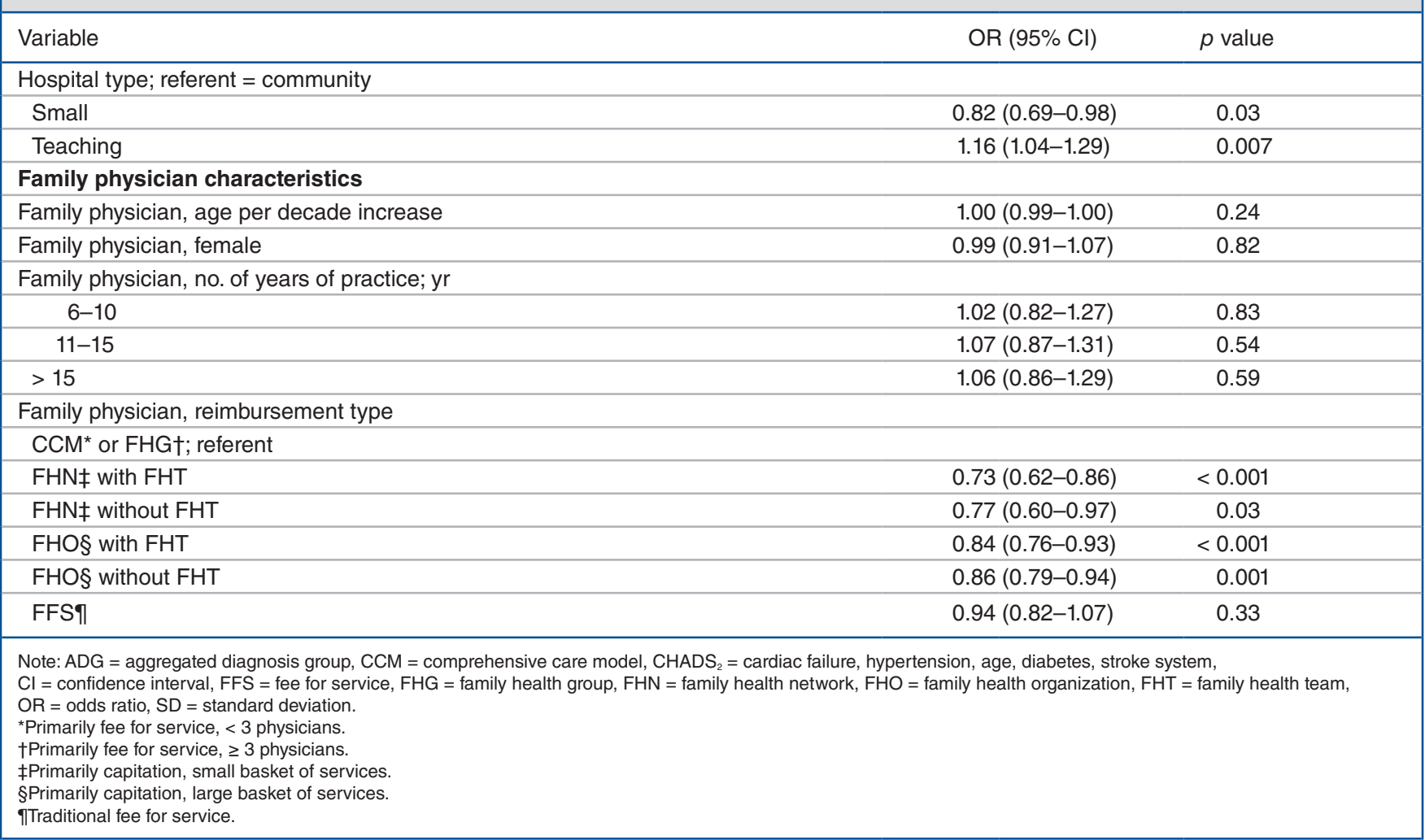


nosis of atrial fibrillation, a cardiovascular disease that can cause a tachycardiomyopathy, should include a physical examination for signs of heart failure, which would not be possible using these communication methods. ${ }^{12,41,42}$ Capitated providers may occasionally forget to submit billing data because it has less impact on earnings. The extent of this is uncertain; however, taken with other reports of lesser access and high emergency department use in the capitation-based models, ${ }^{15}$ it is unlikely that these issues would be sizeable enough to overcome the observed associations.

We included any follow-up visit, regardless of the ICD code listed for the visit; this may have resulted in some misclassification. The family physician, cardiologist and internist co-investigators decided a priori that if a physician in their specialties were to see a patient with a new diagnosis of atrial fibrillation, most would address the atrial fibrillation, regardless of the original intent of the visit, because that would be within their common scope of practice. In turn, we assumed that during the small proportion of visits to other specialists (e.g., orthopedic surgeons, gynecologists) after discharge, the atrial fibrillation was not managed by these practitioners.

\section{Conclusion}

In the province of Ontario, only half of the patients who were discharged from an emergency department with a new diagnosis of atrial fibrillation obtained follow-up care within a week. Having a family physician had the greatest impact on receipt of timely follow-up care, whereas characteristics of the managing emergency department physician were not associated. Access to follow-up care was slower if the family physician remuneration was capitation-based when compared with patients with a family physician who was reimbursed using a blended fee-for-service model or traditional fee-for-service billing claims. Systemswide solutions are needed to ensure timely follow-up care for patients after discharge from an emergency department with a new diagnosis of a cardiovascular disease.

\section{References}

1. Go AS, Hylek EM, Phillips KA, et al. Prevalence of diagnosed atrial fibrillation in adults: national implications for rhythm management and stroke prevention: the AnTicoagulation and Risk Factors in Atrial Fibrillation (ATRIA) Study. 7AMA 2001;285:2370-5.

2. Naccarelli GV, Varker H, Lin J, et al. Increasing prevalence of atrial fibrillation and flutter in the United States. Am 7 Cardiol 2009;104:1534-9.

3. Atrial Fibrillation Investigators. Risk factors for stroke and efficacy of antithrombotic therapy in atrial fibrillation. Analysis of pooled data from five randomized controlled trials. Arch Intern Med 1994;154:1449-57.

4. Gladstone DJ, Spring M, Dorian P, et al. Atrial fibrillation in patients with cryptogenic stroke. N Engl 7 Med 2014;370:2467-77.

5. Marini C, De Santis F, Sacco S, et al. Contribution of atrial fibrillation to incidence and outcome of ischemic stroke: results from a population-based study. Stroke 2005;36:1115-9.

6. Jabre P, Roger VL, Murad MH, et al. Mortality associated with atrial fibrillation in patients with myocardial infarction: a systematic review and metaanalysis. Circulation 2011;123:1587-93.

7. Walkey AJ, Wiener RS, Ghobrial JM, et al. Incident stroke and mortality associated with new-onset atrial fibrillation in patients hospitalized with severe sepsis. FAMA 2011;306:2248-54.

8. Benjamin EJ, Wolf PA, D'Agostino RB, et al. Impact of atrial fibrillation on the risk of death: the Framingham Heart Study. Circulation 1998;98:946-52.

9. Atzema CL, Austin PC, Miller E, et al. A population-based description of atrial fibrillation in the emergency department, 2002 to 2010. Ann Emerg Med 2013;62:570-7.

10. Stiell IG, Macle L. Canadian Cardiovascular Society atrial fibrillation guidelines 2010: management of recent-onset atrial fibrillation and flutter in the emergency department [published erratum in Can 7 Cardiol 2012;28:244]. Can 7 Cardiol 2011;27:38-46.

11. Camm AJ, Kirchhof P, Lip GY, et al. Guidelines for the management of atrial fibrillation: the Task Force for the Management of Atrial Fibrillation of the European Society of Cardiology (ESC). Eur Heart 7 2010;31:2369-429.

12. January CT, Wann LS, Alpert JS, et al. 2014 AHA/ACC/HRS guideline for the management of patients with atrial fibrillation: a report of the American College of Cardiology/American Heart Association Task Force on Practice Guidelines and the Heart Rhythm Society. 7 Am Coll Cardiol 2014;64:e1-76.

13. Dorian P, Jung W, Newman D, et al. The impairment of health-related quality of life in patients with intermittent atrial fibrillation: implications for the assessment of investigational therapy. 7 Am Coll Cardiol 2000;36:1303-9.

14. Critical Decision in Emergency Medicine. ACEP's Official CME Publication. Dallas: American College of Emergency Physicians; 2014. Available: www.acep .org/cdem/ (accessed 2014 June 17).

15. Glazier RH, Klein-Geltink J, Kopp A, et al. Capitation and enhanced fee-forservice models for primary care reform: a population-based evaluation. CMAJ 2009;180:E72-81.

16. Glazier R, Zagorski BM, Rayner J. Comparison of primary care models in Ontario by demographics, case mix, and emergency department use, 2008/09 to 2009/10. Toronto: Institute for Clinical Evaluative Sciences; 2012.

17. Gosden T, Forland F, Kristiansen IS, et al. Capitation, salary, fee-for-service and mixed systems of payment: effects on the behaviour of primary care physicians. Cochrane Database Syst Rev 2000; (3):CD002215.

18. 2011 Census of population and Statististics Canada catalogue no. 98-314-XCB. Ottawa: Statistics Canada; 2010. Available: http://statcan.gc.ca/tables-tableaux/ sum-som/I01/cst01/demo11b-eng.htm (accessed 2015 Apr. 17).

19. Iron K, Zagorski B, Sykora K, et al. Living and dying in Ontario: an opportunit for improved health information. Toronto: Institute for Clinical Evaluative Sciences, 2009. Available: www.ices.on.ca/ /media/Files/Atlases-Reports/2008/ Living-and-dying-in-Ontario/Full\%20report.ashx (accessed 2015 Mar. 30).

20. Physicians in Ontario report. Hamilton (ON): Ontario Physician Human Resource Data Centre; 2014. Available: www.ophrdc.org/Public/Report. aspx? owner=pio (accessed 2015 Mar. 30).

21. Patient rostering in family practice. Mississauga (ON): The College of Family Physicians of Canada; 2012. Available: www.cfpc.ca/uploadedFiles/Health Policy/CFPC_Policy_Papers_and_Endorsements/CFPC_Policy_Papers/ BestAdvice_RosteringFINALOct30.pdf (accessed 2015 Mar.30).

22. Improving access to emergency care: addressing system issues. Toronto: Ontario Hospital Association and Ontario Ministry of Health and Long-Term care; 2006. Available: www.health.gov.on.ca/en/common/ministry/publications/reports/ improving_access/improving_access.pdf (accessed 2015 Mar. 30).

23. Report of the advisory panel on resourcing options for sustainable bealth care in Canada to the Canadian Medical Association. Ottawa: The Canadian Medical Association; 2011.

24. Kripalani S, LeFevre F, Phillips CO, et al. Deficits in communication and information transfer between hospital-based and primary care physicians: implications for patient safety and continuity of care. FAMA 2007;297:831-41.

25. Beveridge R, Clarke B, Janes L, et al. Implementation guidelines for the Canadian Emergency Department Triage \& Acuity Scale (CTAS).Ottawa: Canadian Association of Emergency Physicians; 1998.Available: http://caep.ca/resources/ ctas/implementation-guidelines (accessed 2015 Mar. 31).

26. Austin PC, Daly PA, Tu JV. A multicenter study of the coding accuracy of hospital discharge administrative data for patients admitted to cardiac care units in Ontario. Am Heart 7 2002;144:290-6.

27. Gershon AS, Wang C, Guan J, et al. Identifying individuals with physician diagnosed COPD in health administrative databases. COPD 2009;6:388-94.

28. Hux JE, Ivis F, Flintoft V, et al. Diabetes in Ontario: determination of prevalence and incidence using a validated administrative data algorithm. Diabetes Care 2002;25:512-6.

29. Schultz SE, Rothwell DM, Chen Z, et al. Identifying cases of congestive heart failure from administrative data: a validation study using primary care patient records. Chronic Dis Inj Can 2013;33:160-6.

30. Tu K, Campbell NR, Chen Z, et al. Accuracy of administrative databases in identifying patients with hypertension. Open Med 2007;1:e18-26.

31. Postal Code Conversion File, Reference Guide. Ottawa: Statistics Canada; 2007.

32. Cho DD, Austin PC, Atzema CL. Current practice patterns for the management of discharged emergency department patients with a primary diagnosis of hypertension: a multicentre survey. CFEM. In press.

33. Hernandez AF, Greiner MA, Fonarow GC, et al. Relationship between early physician follow-up and 30-day readmission among Medicare beneficiaries hospitalized for heart failure. 7 AMA 2010;303:1716-22.

34. Fournier J, Heale R, Rietze LL. I can't wait: advanced access decreases wait times in primary healthcare. Healthc Q 2012;15:64-8.

35. McCusker J, Dendukuri N, Tousignant P, et al. Rapid two-stage emergency department intervention for seniors: impact on continuity of care. Acad Emerg Med 2003;10:233-43.

36. Richards D, Meshkat N, Chu J, et al. Emergency department patient compliance with follow-up for outpatient exercise stress testing: a randomized controlled trial. C7EM 2007;9:435-40.

37. Lip GY, Nieuwlaat R, Pisters R, et al. Refining clinical risk stratification for predicting stroke and thromboembolism in atrial fibrillation using a nove 
risk factor-based approach: the euro heart survey on atrial fibrillation. Chest 2010;137:263-72.

38. Gage BF, Waterman AD, Shannon W, et al. Validation of clinical classification schemes for predicting stroke: results from the National Registry of Atrial Fibrillation. FAMA 2001;285:2864-70.

39. Dell'Orfano JT, Patel H, Wolbrette DL, et al. Acute treatment of atrial fibrillation: spontaneous conversion rates and cost of care. Am f Cardiol 1999; 83:788-90, A10.

40. Barrett TW, Vermeulen ML, Self WH, et al. A population-based study comparing the emergency department management of atrial fibrillation between the United States and Ontario, Canada. 7 Am Coll Cardiol. In press.

41. Camm AJ, Lip GY, De CR, et al. 2012 focused update of the ESC Guidelines for the management of atrial fibrillation: an update of the 2010 ESC Guidelines for the management of atrial fibrillation. Developed with the special contribution of the European Heart Rhythm Association. Eur Heart 7 2012; 33:2719-47.

42. Skanes AC, Healey JS, Cairns JA, et al. Focused 2012 update of the Canadian Cardiovascular Society Atrial Fibrillation Guidelines: recommendations for stroke prevention and rate/rhythm control. Can f Cardiol 2012;28:125-36.

Affiliations: Institute for Clinical Evaluative Sciences (Atzema, Yu, Ivers, Rochon, Lee, Schull, Austin), Toronto, Ont.; Division of Emergency Medicine (Atzema, Schull); Division of Cardiology (Lee); Division of Geriatric Medicine (Rochon); Department of Medicine, Department of Family Medicine (Ivers), University of Toronto; Sunnybrook Health Sciences Centre (Atzema, Schull); University Health Network (Lee); Women's College Hospital (Ivers, Rochon), Toronto, Ont.
Contributors: Clare Atzema obtained funding, had full access to all of the data in the study, drafted the manuscript and was responsible for the integrity of the data and the accuracy of the data analysis. Clare Atzema, Peter Austin, Noah Ivers, Bing Yu, Douglas Lee and Paula Rochon contributed to the study concept and design, and analyzed and interpreted the data. Bing Yu and Clare Atzema acquired the data. Clare Atzema, Peter Austin and Bing Yu performed the statistical analysis. Peter Austin, Noah Ivers, Bing Yu, Douglas Lee and Paula Rochon critically revised the manuscript for important intellectual content. All of the authors approved the version to be published and agreed to act as guarantors of the work.

Acknowledgements: This project was supported by a Canadian Institutes of Health Research (CIHR) grant.

The University of Toronto had no involvement in the design or conduct of the study; data management or analysis; or manuscript preparation, review, or authorization for submission. This study was supported by the Institute for Clinical Evaluative Sciences (ICES), which is funded by an annual grant from the Ontario Ministry of Health and Long-Term Care (MOHLTC). The opinions, results and conclusions reported in this paper are those of the authors and are independent from the funding sources. No endorsement by ICES or the Ontario MOHLTC is intended or should be inferred.

Supplemental information: For reviewer comments and the original submission of this manuscript, please see www.cmajopen.ca/content/3/2/ E182/suppl/DC1 